\title{
Antioxidant, antibacterial activity, and phytochemical characterization of Melaleuca cajuputi extract
}

Nazeh M. Al-Abd ${ }^{\text {* }}$, Zurainee Mohamed Nor ${ }^{1}$, Marzida Mansor ${ }^{2}$, Fadzly Azhar ${ }^{3}$, M. S. Hasan² and Mustafa Kassim²

\begin{abstract}
Background: The threat posed by drug-resistant pathogens has resulted in the increasing momentum in research and development for effective alternative medications. The antioxidant and antibacterial properties of phytochemical extracts makes them attractive alternative complementary medicines. Therefore, this study evaluated the phytochemical constituents of Melaleuca cajuputi flower and leaf (GF and GL, respectively) extracts and their antioxidant and antibacterial activities.

Methods: Radical scavenging capacity of the extracts was estimated using 2,2-diphenyl-2-picrylhydrazyl and $\mathrm{Fe}^{2+}$-chelating activity. Total antioxidant activity was determined using ferric reducing antioxidant power assay. Well diffusion, minimum inhibitory concentration, and minimum bactericidal concentration assays were used to determine antibacterial activity against eight pathogens, namely Staphylococcus aureus, Escherichia coli, Bacillus cereus, Staphylococcus epidermidis, Salmonella typhimurium, Klebsiella pneumonia, Streptococcus pneumoniae, and Pasteurella multocida. We identified and quantified the phytochemical constituents in methanol extracts using liquid chromatography/mass spectrometry (LC/MS) and gas chromatography (GC)/MS.

Results: This study reports the antioxidant and radical scavenging activity of $M$. cajuputi methanolic extracts. The GF extract showed better efficacy than that of the GL extract. The total phenolic contents were higher in the flower extract than they were in the leaf extract $(0.55 \pm 0.05$ and $0.37 \pm 0.05$ gallic acid equivalent per mg extract dry weight, respectively). As expected, the percentage radical inhibition by GF was higher than that by the GL extract ( 81 and $75 \%$, respectively). A similar trend was observed in $\mathrm{Fe}^{2+}$-chelating activity and $\beta$-carotene bleaching tests. The antibacterial assay of the extracts revealed no inhibition zones with the Gram-negative bacteria tested. However, the extracts demonstrated activity against B. cereus, S. aureus, and S. epidermidis.
\end{abstract}

Conclusions: In this study, we found that M. cajuputi extracts possess antioxidant and antibacterial activities. The results revealed that both extracts had significant antioxidant and free radical-scavenging activity. Both extracts had antibacterial activity against S. aureus, S. epidermidis, and B. cereus. The antioxidant and antimicrobial activities could be attributed to high flavonoid and phenolic contents identified using GC/MS and LC/MS. Therefore, $M$. cajuputi could be an excellent source for natural antioxidant and antibacterial agents for medical and nutraceutical applications.

Keywords: Melaleuca cajuputi, Antioxidant capacity, Total phenol content, Gas chromatography/mass spectrometry (GC/MS), Liquid chromatography/mass spectrometry (LC/MS)

\footnotetext{
* Correspondence: Nazehali78@yahoo.com

${ }^{1}$ Department of Parasitology, Faculty of Medicine, University of Malaya, 50603

Kuala Lumpur, Malaysia

Full list of author information is available at the end of the article
} 


\section{Background}

The cells of living organisms generate free-radicals as a result of pathophysiological and biochemical processes in response to factors such as environmental pollutants, radiation, chemicals, and toxins. This creates an imbalance in the formation and neutralization of prooxidants that subsequently seek stability through electron pairing with biological macromolecules such as proteins, lipids, and DNA, leading to oxidative stress in the physiological system [1]. Furthermore, these effects lead to lipid peroxidation as well as protein or DNA damage or both in human cells. Moreover, the cellular damage consequently lead to aging and several chronic diseases such as cancer, diabetes, and atherosclerosis as well as cardiovascular, inflammatory, and other degenerative diseases in humans [1]. The ability of certain phytochemical extracts to inhibit or delay the oxidation of other molecules by suppressing the initiation or propagation of oxidizing chain reactions have made them active alternatives in complementary medicine. These naturally occurring antioxidant chemicals have been reported to be composed of phenolic (such as flavonoids, phenolic acids, and tocopherols) and nitrogen compounds (alkaloids, chlorophyll derivatives, amines, and amino acids) as well as carotenoids and ascorbic acid [2]. In fact, phytochemical extracts containing constituents such as plant-derived vitamins, flavonoids, alkaloids carotenoids, terpenoids, polyphenols, and phenolic compounds such as caffeic, vanillic, ferulic, and ellagic acids have been reported to exhibit antioxidant and anticancer activities [3].

Although chemically synthesized antioxidant compounds such as butylated hydroxytoluene and hydroxyanisole have been used for several decades, the safety of their continued use is currently being questioned due to reports of their carcinogenicity [4]. Therefore, alternative effective antioxidants that have benign or minimal side effects are highly needed.

Infectious diseases caused by microorganism are a major cause of mortality and morbidity in humans. Although several antibiotics have been developed to manage these diseases with optimum efficacy, their mismanagement and maladministration, as well as microbial mutation have led to the emergence of drug-resistant strains. As a result, over the past decades, antibiotics that are known to cure specific diseases have lost their effectiveness. Therefore, the search for new antimicrobial drugs from natural sources is warranted.

Traditional medicine practices in ancient human civilizations worldwide have demonstrated that plants are one of the most promising sources of effective medicinal agents. Therefore, scientific studies have been carried out on the antimicrobial activities of plant extracts against different types of microorganisms, which have resulted in the development of alternative plant-based antimicrobial drugs.
Numerous phytochemical extracts have been evaluated in the process of searching for plant-based antimicrobial agents and some recently reported studies include those on Syzygium gratum, Justicia gangetica, and Limnocharis flava [5], Buglossoides purpurocaerulea [6], Nymphaea nouchali [7], and Polygonum hydropiper [8]. Melaleuca cajuputi is commonly known as the Gelam tree and is used to cure cholera as well as muscle and joint pain in folk medicine. It is a member of the Myrtaceae family with reported anti-inflammatory [9], anticancer [10], hepatoprotective [11], and anthelmintic activities [12]. Studies have revealed the antibacterial activity of essential oils of $M$. caguputi against Gram-positive and Gram-negative bacterial strains in the disc diffusion and minimum inhibitory concentration (MIC) assays. The extracted oil inhibited the growth of Enterococcus faecalis, Escherichia coli, Klebsiella pneumoniae, Pseudomonas aeruginosa, Salmonella enterica, Staphylococcus aureus, and Streptococcus pyogenes [13, 14].

In this study, we evaluated the in vitro antioxidant and antibacterial activities of methanolic extracts of the leaves and flowers of $M$. cajuputi. In addition, we analyzed the phytochemical constituents of the extracts using liquid chromatography (LC)/mass spectrometry (MS) and gas chromatography (GC)/MS.

\section{Methods}

\section{Chemical and reagents}

Methanol, sodium hydroxide $(\mathrm{NaOH})$, iron (II) sulfate $\left(\mathrm{FeSO}_{4}\right)$, iron (II) chloride $\left(\mathrm{FeCl}_{2}\right)$, sodium nitrite, iron (II) chloride $\left(\mathrm{FeCl}_{3}\right)$, chloroform, hydrochloric acid (HCL), $\beta$ carotene, quercetin, chloragenic acid, tripyridyl-s-triazine (TPTZ), butylated hydroxytoluene (BHT), propyl gallate, 2,2-diphenyl -1- picrylhydrazyl (DPPH), linoleic acid, Tween 20, Folin-ciocalteu reagent, acetate buffer, ferrozine, ethylenediaminetetraacetic acid (EDTA), ascorbic acid, and all other reagents and solvents used in this study were of analytical grade purchased from Merck (Merck, Darmstadt, Germany).

\section{Plant materials}

The plant material used in this study was collected from Kedah State, Malaysia, in September 2013, and Identity was confirmed at the Herbarium of Rimba Ilmu, Institute of Biological Sciences, University of Malaya, Kuala Lumpur with voucher number KLU048231.

\section{Preparation of methanolic extracts}

The leaves and flowers of the Gelam tree (M. cajuputi) were washed separately with distilled water, ground to a powder, and then dried in the shade for seven days. The methanolic extracts were prepared by adding $100 \mathrm{~g}$ of either the Gelam leaves (GL) or Gelam flower (GF) powder to $1 \mathrm{~L}$ of absolute methanol in a conical flask and leaving it 
for $72 \mathrm{~h}$ at $25^{\circ} \mathrm{C}$. The mixtures were then filtered using Whatman filter paper (No: 1) to obtain the extract and this procedure was repeated thrice, followed by in vacuo concentration at $40{ }^{\circ} \mathrm{C}$ using a rotary evaporator to obtain the GF and GL extracts.

\section{GC/MS analysis}

The GC/MS analysis of the methanol extract was carried out by sonicating a $10-\mathrm{mg}$ sample for $15 \mathrm{~min}$ in $2.5 \mathrm{~mL}$ of dichloromethane at $40{ }^{\circ} \mathrm{C}$ in a sealed vial. Then, $1 \mathrm{~mL}$ of the treated extract sample was filtered through a $0.20-\mu \mathrm{m}$ nylon filter into a standard GC $2-\mathrm{mL}$ vial for analysis. The GC/MS analyses were performed at an ionization energy of $70 \mathrm{eV}$ while separation of the hydrocarbons and other volatile compounds were determined using a GCMS-QP2010 series GC system (Shimadzu, Japan) equipped with a DB-5MS Agilent nonpolar column $(30 \mathrm{~mm} \times 0.25 \mathrm{~mm}$, $0.25 \mathrm{~mm}$ ) (Agilent Technologies Inc., Tokyo, Japan). The oven was initially programmed to run at a temperature of $60{ }^{\circ} \mathrm{C}$ for $2 \mathrm{~min}$, followed by an increase of $7{ }^{\circ} \mathrm{C} / \mathrm{min}$ to $150{ }^{\circ} \mathrm{C}$, with a final hold at $310^{\circ} \mathrm{C}$ for $15 \mathrm{~min}$. The injector and detector temperatures were kept at 300 (split) and $310{ }^{\circ} \mathrm{C}$, respectively. The analysis was performed with $\mathrm{He}$ as the carrier gas at a linear flow rate of $40 \mathrm{~cm} / \mathrm{s}$, and the MS detector was operated at $200{ }^{\circ} \mathrm{C}$ while the scan range was from $50-1000 \mathrm{~m} / \mathrm{z}$ at a rate of $0.50 \mathrm{scan} / \mathrm{s}$. To check the purity of each GC peak, the MS was recorded at various parts of each peak. All compounds were putatively identified using a mass spectral database search (National Institute of Standards and Technology/ Environmental Protection Agency/National Institutes of Health, NIST/ EPA/NIH) followed by a comparison with the acquired MS data to determine the degree of matching. The compounds that showed mass spectra with match factors $\geq 90 \%$ were included on the "positive list" of tentatively identified metabolites.

\section{LC/MS analysis}

The LC/MS experiments were conducted to chemically profile the methanolic extracts. The system used to analyze the samples was comprised of an Agilent 1290 Infinity LC system coupled to an Agilent 6520 Accurate-Mass quadrupole time-of-flight mass spectrometer with dual electrospray ionization (ESI) source. The LC separations were performed using a $2.1 \mathrm{~mm}$ (i.d) Narrow-BoreSB-C18 (length $150 \mathrm{~mm}$, particle size $3.5 \mathrm{mM}$ ) analytical column. The LC parameters used were: autosampler temperature, $25{ }^{\circ} \mathrm{C}$; injection volume, $0.5 \mu \mathrm{L}$; column temperature, $25^{\circ} \mathrm{C}$; and flow rate, $0.4 \mathrm{~mL} / \mathrm{min}$. A gradient system consisting of solvents A ( $0.1 \%$ formic acid in water) and B ( $0.1 \%$ formic acid in acetonitrile) was employed. The mass spectra data were acquired using an ESI capillary voltage of (+) $4000 \mathrm{~V}$ and $(-) 4000 \mathrm{~V}$ in the positive and negative ion modes, respectively with the fragmentor at $125 \mathrm{~V}$. For the other conditions, the liquid nebulizer was set to $45 \mathrm{psi}$, the nitrogen drying gas was set at a flow rate of $10 \mathrm{~L} /$ min with the drying gas and vaporizer temperatures maintained at $300{ }^{\circ} \mathrm{C}$, and the ionization interface was operated in both positive and negative modes. The data were acquired at a rate of 1.03 spectra/s with a stored mass range of $100-3200$ and $115-3200 \mathrm{~m} / \mathrm{z}$ for the positive and negative modes, respectively. The data were collected using the Agilent Mass Hunter Workstation Data acquisition software. LC/MS data files were processed using the Agilent Mass Hunter Qualitative Analysis B.05.00 software. Feature finding was achieved by using the molecular feature extraction and correlation algorithms, which located the groups of covariant ions in each chromatogram. In the positive-ion mode, this included adducts $\mathrm{H}^{+}, \mathrm{Na}^{+}, \mathrm{K}^{+}$, and $\mathrm{NH}_{4}^{+}$and in the negative-ion mode, adducts $\mathrm{H}^{-}$and $\mathrm{Cl}^{-}$.

\section{Total flavonoid assay}

The total flavonoid content of the methanolic extracts was determined photometrically using the aluminum chloride $\left(\mathrm{AlCl}_{3}\right)$ assay [15]. Briefly, a 1-mL aliquot of each extract $(1 \mathrm{mg} / \mathrm{mL})$ or standard solution of quercetin (31.5, 62.5, $125,250,500$, and $1 \mathrm{mg} / \mathrm{L}$ ) was added to a volumetric flask (10-mL) and diluted with $4 \mathrm{~mL}$ double distilled water at time 0 . Then, $0.3 \mathrm{~mL}$ of $5 \%(\mathrm{w} / \mathrm{v})$ sodium nitrite $\left(\mathrm{NaNO}_{2}\right)$ was added and after $5 \mathrm{~min}, 0.6 \mathrm{~mL} \mathrm{AlCl}_{3}$ (10\%) was added. At $6 \mathrm{~min}, 2 \mathrm{~mL}$ of sodium hydroxide $(\mathrm{NaOH}, 1 \mathrm{M})$ was added to the mixture, and the final total volume was made up to $10 \mathrm{~mL}$ with double-distilled water. The solution was mixed completely, and the absorbance was measured against a prepared reagent blank in triplicate at $430 \mathrm{~nm}$. The total flavonoid content was expressed as quercetin equivalents in $\mathrm{mg} / 100 \mathrm{~g}$ of dry extract weight.

\section{Total phenolic content (TPC)}

The TPC of the methanolic extracts was determined using the Folin-Ciocalteu reagent (Sigma-Aldrich Chemical Co., St. Louis, MO, USA) as previously described by Kim et al. [16], with slight modifications. Briefly, $100 \mu \mathrm{L}$ of each extract or standard solution of gallic acid (16$1000 \mu \mathrm{g} / \mathrm{mL}$ in $80 \%$ methanol) was mixed with $200 \mu \mathrm{L}$ of Folin-Ciocalteu reagent, followed by $2 \mathrm{~mL}$ of deionized water and $1 \mathrm{~mL}$ of $15 \%$ sodium bicarbonate $\left(\mathrm{Na}_{2} \mathrm{CO}_{3}\right)$. Then, the mixture was incubated for $120 \mathrm{~min}$ at room temperature, and the absorbance was measured at $765 \mathrm{~nm}$ in triplicate using an ultraviolet (UV)-Visible (Vis) spectrophotometer (GBC, Cintra 40). The total phenolics were quantified using a calibration curve constructed from measurements of the standard gallic acid concentrations and expressed as mg gallic acid equivalent (GAE) per mg of extract weight. 


\section{Determination of antioxidant activity using DPPH radical scavenging}

The antioxidant activity of the extracts was measured by determining the hydrogen donating or radical scavenging ability, using the stable radical, DPPH as reported previously [17]. An aliquot $(120 \mu \mathrm{L})$ of $0.25 \mathrm{mM} \mathrm{DPPH}$ solution in methanol and $30 \mu \mathrm{L}$ of each extract at increasing concentrations $(31.3,62.5,125,250,500$, and $1000 \mu \mathrm{g} / \mathrm{mL}$ ) were mixed vigorously together and left at room temperature in the dark. The absorbance was measured at $518 \mathrm{~nm}$ after $30 \mathrm{~min}$ against different concentrations of the extracts in methanol as blanks and DPPH in methanol without extract as the control. The standard synthetic antioxidant, butylhydroxytoluene was used as the positive control. The percentage antiradical activity (AA\%) of the extracts was calculated using the following formula [15],

$$
A A \%=\left(100-\left(\frac{A b s_{\text {sample }}-A b s_{\text {blank }}}{A b s_{\text {control }}}\right) \times 100\right)
$$

Where, $\mathrm{Abs}_{\text {sample }}, \mathrm{Abs}_{\text {blank }}$, and $\mathrm{Abs}_{\text {control }}$ are the absorbance values of the extract, blank, and control samples, respectively.

\section{$\beta$-Carotene bleaching test}

The $\beta$-carotene bleaching test was used to evaluate the antioxidant activities based on the $\beta$-carotene lenolate system model [18], with slight modifications. Briefly, $1 \mathrm{~mL}$ of $\beta$-carotene solution $(0.2 \mathrm{mg} / \mathrm{mL}$ in chloroform) was added to $0.02 \mathrm{~mL}$ of linoleic acid and $0.2 \mathrm{~mL}$ of $100 \%$ Tween 20. Then, $5 \mathrm{~mL}$ samples of this emulsion were transferred into test tubes containing $0.2 \mathrm{~mL}$ of test samples in $80 \%$ methanol at increasing concentrations $(62.5,125,250,500$, and $1000 \mu \mathrm{g} / \mathrm{mL})$. These mixtures were then incubated in a water bath at $40{ }^{\circ} \mathrm{C}$ for $120 \mathrm{~min}$. All determinations were performed in duplicate and the mean values calculated. The absorbance was measured at $470 \mathrm{~nm}$ using a Perkin-Elmer Lambda 40 $\mathrm{UV} / \mathrm{Vis}$ spectrophotometer against a blank consisting of the emulsion without $\beta$-carotene. The measurements were carried out at initial and final times $(t=0$ and $120 \mathrm{~min}$, respectively) with propyl gallate as the positive control. The AA\% was measured and expressed as the percentage of inhibition of $\beta$-carotene oxidation using the following equation:

$$
A A \%=\left[\left(\frac{A S_{0}-A S_{120}}{A C_{0}-A C_{120}}\right)\right] \times 100
$$

Where $\mathrm{AS}_{0}$ and $\mathrm{AS}_{120}$ are absorbance values of the samples and $\mathrm{AC}_{0}$, and $\mathrm{AC}_{120}$ are the controls at 0 and $120 \mathrm{~min}$, respectively.

\section{$\mathrm{Fe}^{2+}$-chelating activity assay}

The $\mathrm{Fe}^{2+}$-chelating activity of GL and GF extracts was measured as follows: The extract was treated with ferrozine $(5 \mathrm{mM})$, which reacted with the divalent iron to form a stable and highly water-soluble magenta complex species. After $10 \mathrm{~min}$ at room temperature, the absorbance of the $\mathrm{Fe}^{2+-}$ ferrozine complex was measured at $562 \mathrm{~nm}$. The $\mathrm{Fe}^{2+}$-chelating activity of the extract was calculated using the following equation:

$$
\% \text { Chelating rate }=\frac{\mathrm{A} 0-\mathrm{A} 1}{\mathrm{~A} 0} \times 100
$$

Where, $\mathrm{A}_{0}$ and $\mathrm{A}_{1}$ are the absorbance values of the control (blank without extract) and in the presence of the extract, respectively.

\section{Ferric reducing antioxidant power (FRAP) assay}

The ferric reducing power of the extracts was assayed based on the blue coloration that developed due to the reduction of ferric iron to the ferrous form as described previously [18]. Extract solutions were prepared by dissolving about $0.1 \mu \mathrm{g} / \mathrm{mL}$ of extracts in ethanol. An aliquot $(0.2 \mathrm{~mL})$ of each extract solution was added to a test tube containing $1.8 \mathrm{~mL}$ of freshly prepared FRAP reagent that consisted of $2.5 \mathrm{~mL}$ of $10 \mathrm{mM}$ TPTZ solution in $40 \mathrm{mM}$ of $\mathrm{HCl}$ and $2.5 \mathrm{~mL}$ of $20 \mathrm{mM} \mathrm{FeCl}_{3} \cdot 6 \mathrm{H}_{2} \mathrm{O}$ in $25 \mathrm{~mL}$ of $0.3 \mathrm{M}$ acetate buffer ( $\mathrm{pH}$ 3.6). The mixture was incubated at $37{ }^{\circ} \mathrm{C}$ for $5 \mathrm{~min}$. The spectrometric absorbance was recorded at $593 \mathrm{~nm}$. The reducing power was ascertained by comparing the spectrophotometric absorbance of each sample against a standard curve obtained from $\mathrm{Fe}_{2} \mathrm{SO}_{4}$.

\section{Antimicrobial activity Test organisms}

The in vitro antibacterial activities of the $M$. cajuputi extracts were evaluated against eight strains that were supplied by the Microbiology Laboratory of the University of Malaya Medical Centre. They comprised of four Gram-positive (Staphylococcus epidermidis, MTCC 3615; Staphylococcus aureus, RF 122; Bacillus cereus, ATCC 11778; and Streptococcus pneumoniae, ATCC 10015) and four Gram-negative (Escherichia coli, UT181; Salmonella typhimurium, ATCC 14028; Klebsiella pneumonia, ATCC13883; and Pasteurella multocida, a clinically isolated strain) bacterial strains. All the strains were stored in the appropriate medium before use.

\section{Inocula preparation}

The colony suspension method was used to prepare the inocula of the test organisms. The bacterial strains were grown on nutrient agar (NA) at $37{ }^{\circ} \mathrm{C}$ for $18 \mathrm{~h}$, and then adjusted to a turbidity of 0.5 McFarland standards $\left(10^{6}\right.$ 
colony forming units, CFU/mL) based on the optical density (OD) measurement at $620 \mathrm{~nm}$. After being cultured for $24 \mathrm{~h}$ on NA, the colonies were collected, and cultured in nutrient broth medium for $24 \mathrm{~h}$ at $37{ }^{\circ} \mathrm{C}$. The susceptibility tests were subsequently performed using the NA-well diffusion method.

\section{Bacterial cultures and disc diffusion assay}

The disc diffusion method is a widely acclaimed method used in screening crude extracts for antibacterial activities. In this study, the antibacterial activity was determined based on the method previously described [19] with modifications. Briefly, the crude extract at a concentration of $0.1 \mathrm{~g} / \mathrm{mL}$ was dissolved in $100 \%$ dimethyl sulfoxide (DMSO, Merck, Germany) and sterilized by filtration using a $0.20-\mathrm{mm}$ Millipore disposable filter (Minisart, Sartorius Biotech, Germany). Autoclave-sterilized $\left(121{ }^{\circ} \mathrm{C}\right.$ for $20 \mathrm{~min}$ ) Mueller Hinton Agar (MHA) medium (BioLab) was used in the disc diffusion assay. A 50- $\mathrm{L}$ sample of the filtration-sterilized plant extract was loaded onto a sterile paper disc (6 $\mathrm{mm}$ in diameter), which was then placed on the surface of the agar plate (NA) previously inoculated with the bacteria. A disc prepared under the same conditions with only $50 \mu \mathrm{L}$ of DMSO was used as a negative control. In addition, a similar disc was loaded with the reference antibiotic (streptomycin) at a concentration of $20 \mathrm{mg}$ of drug per disc and used as described above. Both samples were allowed to diffuse into the agar plates for $1 \mathrm{~h}$ and were then inverted and incubated at $37^{\circ} \mathrm{C}$ for $18 \mathrm{~h}$. Antibacterial activity was determined by measuring the diameter of the growth inhibition zones (IZs, $\mathrm{mm}$ ) surrounding each disc. Each assay was performed in triplicate with two repetitions and the results were expressed as average values.

\section{MIC and minimal bactericidal concentration (MBC) assays} The MIC values, which represent the lowest plant extract concentration that completely inhibits the growth of microorganisms, were determined using a micro-well dilution method as described previously [20]. In addition, the $\mathrm{MBC}$ values refer to the lowest concentration of an antibacterial agent required to prevent the growth of a particular bacterium after subculture in an antibiotic-free medium. Briefly, the extracts were dissolved in DMSO at $100 \mathrm{mg} / \mathrm{mL}$, and then twofold serial dilutions were prepared in a 96-well dilution microplate. The antibiotic streptomycin was included as reference agent in each assay while the extract-free solution was used as a blank control. Each well of the microplates contained $40 \mu \mathrm{L}$ of growth medium, $10 \mu \mathrm{L}$ of inoculum $\left(10^{6} \mathrm{CFU} / \mathrm{ml}\right)$, and $50 \mu \mathrm{L}$ of diluted sample extracts. Then, the microplates were incubated overnight at $37{ }^{\circ} \mathrm{C}$. As an indicator of microorganism growth, $40 \mu \mathrm{L}$ of p-iodo nitro tetrazolium violet (INT) dissolved in water was added to the wells, and the plates were incubated at $37{ }^{\circ} \mathrm{C}$ for $30 \mathrm{~min}$. The colorless tetrazolium salt acts as an electron acceptor and is reduced to a red-colored formazan product by biologically active organisms [20]. A Tecan microplate reader (Infinite M200PRO) was used to quantify the OD of the reactants in each well. Where microbial growth was inhibited, the solution in the well remained clear after incubation with INT. The determination of MIC values was performed in triplicate. The $\mathrm{MBC}$ of the extracts was determined by subculturing samples from the MIC assay tubes onto NA plates from wells that showed growth inhibition, and then subsequently determining the dilution at which growth was arrested, which was considered the MBC.

\section{Statistical analysis}

The data were expressed as mean \pm standard deviation (SD) of triplicate determinations. The half-maximal inhibitory concentrations $\left(\mathrm{IC}_{50}\right)$ values were estimated from the $\mathrm{AA} \%$ versus concentration plots using a non-linear regression algorithm.

\section{Results and discussion}

In this study, we evaluated the chemical constituents of GL and GF using preliminary GC/MS and LC/MS analysis. Furthermore, we determined their antioxidant and antibacterial activities using various in vitro methods.

\section{GC/MS and LC/MS analysis of GF and GL from $M$. cajuputi}

The phytochemical analyses of plant extracts are normally performed using diverse quantitative and qualitative analytical techniques spanning from chromatography to spectroscopy [21]. Previously, K-L Li and S-J Sheu [22] used a micellar electrokinetic capillary chromatographic method to analyze the phytochemical constituents of scute-coptis, a dual herbal combination. Using this method, the researchers identified six scute flavonoids namely baicalin, wogonin 7-O-glucuronide, oroxylin A 7-O-glucuronide, baicalein, wogonin, and oroxylin A as well as four coptis alkaloids comprising of berberine, palmatine, coptisine, and epiberberine.

In another study, GC/MS was used to characterize the chemical content of Melaleuca essential oils [23-25]. Similarly, silica gel chromatography was used to isolate a new chromone from M. cajuputi leaf extracts [26]. Using a combination of spectroscopic techniques, the study characterized the newly isolated chromonone as melachromone [26].

Similarly, in this study, preliminary compound identification and quantitation was performed using GC/MS and LC/MS. As expected, flavonoids and alkaloids were consistently present in all samples. Furthermore, the occurrence of terpenoids, saponins, glycosides, and steroids depended on the type of plant part extract analyzed. The occurrence of the identified compounds mentioned in Tables 1, 2 and 3 
Table 1 List of major compounds identified from M. cajuputi Laef extract

\begin{tabular}{|c|c|c|c|c|c|c|}
\hline $\mathrm{ID}$ & Posibble Compound Name & Class of compound & Mol. formula & Mol mass & Rt time (min) & $\%$ \\
\hline 1 & 3-Cyclohexen-1-ol & Terpenoids & $\mathrm{C} 18 \mathrm{H} 180$ & 154 & 6.152 & 1.08 \\
\hline 2 & Cyclohexane, 1-ethenyl-1-methyl-2,4bis(1-methylethenyl) & Terpenoids & $\mathrm{C} 15 \mathrm{H} 24 \mathrm{O} 4$ & 204 & 8.109 & 1.83 \\
\hline 3 & Caryophyllene Bicyclo[7.2.0]undec-4ene & Terpenoids & $\mathrm{C} 15 \mathrm{H} 24$ & 204 & 8.589 & 3.64 \\
\hline 4 & Caryophyllene 1,4,8-Cycloundecatriene & Terpenoids & $\mathrm{C} 15 \mathrm{H} 24$ & 204 & 9.061 & 2.32 \\
\hline 5 & Naphthalene & Terpenoids & $\mathrm{C} 15 \mathrm{H} 24$ & 204 & 9.537 & 2.13 \\
\hline 6 & Naphthalene & Terpenoids & $\mathrm{C} 15 \mathrm{H} 24$ & 204 & 9.619 & 1.66 \\
\hline 7 & 1H-Cycloprop[e]azulen-7-ol & Terpenoids & $\mathrm{C} 15 \mathrm{H} 24 \mathrm{O}$ & 220 & 10.914 & 2.27 \\
\hline 8 & Caryophyllene oxide 5-Oxatricyclo[8.2.0.0(4,6)-]dodecane & Terpenoids & $\mathrm{C} 15 \mathrm{H} 24 \mathrm{O}$ & 220 & 11.046 & 2.0 \\
\hline 9 & Alpha.-Tetralone & Aromatic & $\mathrm{C} 12 \mathrm{H} 13 \mathrm{FO} 3$ & 224 & 11.308 & 7.0 \\
\hline 10 & 2-Naphthalenemethano & Sesquiterpene & $\mathrm{C} 15 \mathrm{H} 24 \mathrm{O}$ & 222 & 12.325 & 2.38 \\
\hline 11 & Spathulenol 1H-Cycloprop[e]azulen-7ol & Sesquiterpene & $\mathrm{C} 15 \mathrm{H} 24 \mathrm{O}$ & 222 & 13.636 & 1.31 \\
\hline 12 & Ethanone & Phenolic & $\mathrm{C} 10 \mathrm{H} 10 \mathrm{O} 5$ & 210 & 15.181 & 2.83 \\
\hline 13 & $3,7,11,15$-Tetramethyl-2-hexadecen-1ol \$ (2E)-3 & Fatty acid & $\mathrm{C} 2 \mathrm{OH} 40 \mathrm{O}$ & 296 & 15.708 & 2.50 \\
\hline 14 & 3-Eicosyne 3-Icosyne & Straight chain & $\mathrm{C} 2 \mathrm{OH} 38$ & 278 & 16.634 & 0.87 \\
\hline 15 & 4H-1-Benzopyran-4-one & Flavone & $\mathrm{C} 11 \mathrm{H} 10 \mathrm{O} 4$ & 206 & 16.791 & 1.38 \\
\hline 16 & 1,4-Naphthalenedione & Aromatic & $\mathrm{C} 11 \mathrm{H} 8 \mathrm{O} 5$ & 220 & 18.750 & 4.53 \\
\hline 17 & 4H-1-Benzopyran-4-one & Flavonoids & $\mathrm{C} 11 \mathrm{H} 8 \mathrm{O} 5$ & 220 & 19.298 & 6.09 \\
\hline 18 & Ethanone & phenolic & $\mathrm{C} 16 \mathrm{H} 14 \mathrm{O} 4$ & 234 & 19.713 & 8.81 \\
\hline 19 & Methyl lathodoratin & Flavonoids & $\mathrm{C} 12 \mathrm{H} 12 \mathrm{O} 4$ & 220 & 20.921 & 0.57 \\
\hline 20 & Phytol 2-Hexadecen-1- & Fatty acids & $\mathrm{C} 2 \mathrm{OH} 40 \mathrm{O}$ & 296 & 21.666 & 0.57 \\
\hline 21 & Octadecanoic acid & Fatty acid & $\mathrm{C} 22 \mathrm{H} 44 \mathrm{O} 2$ & 340 & 27.517 & 1.31 \\
\hline 22 & 1-Heptacosanol & Straight chain & $\mathrm{C} 27 \mathrm{H} 56 \mathrm{O}$ & 396 & 33.437 & 0.27 \\
\hline 23 & Squalene & Straight chain alkene & $\mathrm{C} 30 \mathrm{H} 50$ & 410 & 35.458 & 2.05 \\
\hline 24 & 1-Heptacosanol & Straight chain & $\mathrm{C} 27 \mathrm{H} 56 \mathrm{O}$ & 396 & 33.437 & 0.27 \\
\hline 25 & $2 \mathrm{H}, 6 \mathrm{H}$-Pyrano[3,2-b]xanthen-6-one & Flavonoids & $\mathrm{C} 18 \mathrm{H} 14 \mathrm{O} 6$ & 326 & 39.607 & 0.41 \\
\hline 26 & Alpha Tocopherol (vit E) & Phenolic & $\mathrm{C} 29 \mathrm{H} 50 \mathrm{O} 2$ & 430 & 43.406 & 2.37 \\
\hline 27 & Sitosterol, Stigmast-5-en-3-ol & Terpenoids & $\mathrm{C} 29 \mathrm{H} 50 \mathrm{O}$ & 414 & 43.406 & 2.37 \\
\hline 28 & Urs-12-en-28-al & Terpenoids & $\mathrm{C} 30 \mathrm{H} 48 \mathrm{O}$ & 424 & 44.485 & 0.95 \\
\hline 29 & Dammarane-3,12,25-triol & Terpenoids & & 562 & 47.086 & 0.55 \\
\hline 30 & Betulin Lup-20(29)-ene-3,28-diol & Terpenoids & $\mathrm{C} 30 \mathrm{H} 50 \mathrm{O} 2$ & 482 & 47.947 & 1.15 \\
\hline 31 & Urs-12-en-28-al & Terpenoids & $\mathrm{C} 30 \mathrm{H} 48 \mathrm{O}$ & 424 & 50.881 & 0.96 \\
\hline
\end{tabular}

in this study has been previously reported in Melaleuca extracts $[27,28]$.

As it can be seen in Table 1, the GC/MS analysis of the GF revealed that the major compounds are essential oils, characterized by the presence of fatty acids including octadecanoic (0.68\%), hexadecanoic (0.60\%), and 9,12-octadecadienoic acids (1.90\%). Additionally, there were phenolic compounds such as alpha-tocopherol (vitamin E, $0.47 \%$ ), ethanone (4.34 \%), 1,4-naphthalenedione (1.07\%), and terpenoid compounds such as Urs12-en-28-al (6.40 \%). Furthermore, aromatic compounds such as naphthalene (7.92 \%) and alpha-tetralone (6.24 \%) were detected. Previous studies have demonstrated that some of the identified compounds in the GF extract such as alpha-tocopherol [29] and hexadecanoic acid [30] possess antioxidant activities.

GC/MS analysis of the GL extract revealed the presence of 31 phytochemical compounds. As shown in Table 2, the methanol extract predominantly contained aromatic compounds such as alpha-tetralone (7\%) and 1,4-naphthalenedione (4.53\%); phenolic compounds such as ethanone (11.6\%); terpenoids such as caryophyllene bicyclo [7.2.0] undec-4ene (3.64\%), naphthalene (3.79\%), and sitosterol (2.37\%); and flavonoids such as 4H-1-benzopyran-4-one (6.09\%). In addition, squalene (2.05\%) and octadecanoic acid $(1.31 \%)$ were also present. Furthermore, numerous 
Table 2 List of major compounds identified from Gelam flower extract

\begin{tabular}{|c|c|c|c|c|c|c|}
\hline ID & Posibble Compound Name & Class of compound & Mol. formula & Mol mass & Rt time (min) & $\%$ \\
\hline 1 & 3-Cyclohexen-1-ol & Terpenoid & $\mathrm{C} 18 \mathrm{H} 18 \mathrm{O}$ & 154 & 6.151 & 1.07 \\
\hline 2 & Cyclohexane, 1-ethenyl-1-methyl-2-(1 methylethenyl)-4-(1-methylethylidene)- & Terpenoid & $\mathrm{C} 15 \mathrm{H} 24$ & 204 & 7.482 & 0.68 \\
\hline 3 & Copaene & Terpenoid & $\mathrm{C} 15 \mathrm{H} 24$ & 204 & 7.997 & 1.66 \\
\hline 4 & Cyclohexane, 1-ethenyl-1-methyl-2,4bis(1-methylethenyl) & Terpenoid & $\mathrm{C} 15 \mathrm{H} 24 \mathrm{O} 4$ & 204 & 8.107 & 2.60 \\
\hline 5 & Caryophyllene Bicyclo[7.2.0]undec-4ene & Terpenoid & $\mathrm{C} 15 \mathrm{H} 24$ & 204 & 8.588 & 6.14 \\
\hline 6 & 1,6-Cyclodecadiene, 1-methyl-5methylene-8-(1-methylethyl)-, & Terpenoid & $\mathrm{C} 15 \mathrm{H} 24$ & 204 & 8.690 & 1.49 \\
\hline 7 & Caryophyllene 1,4,8-Cycloundecatriene & Terpenoid & $\mathrm{C} 15 \mathrm{H} 24$ & 204 & 9.059 & 3.16 \\
\hline 8 & Naphthalene & Aromatics & $\mathrm{C} 15 \mathrm{H} 24$ & 204 & 9.536 & 3.26 \\
\hline 9 & Naphthalene & Aromatics & $\mathrm{C} 15 \mathrm{H} 24$ & 204 & 9.616 & 2.66 \\
\hline 10 & Naphthalene & Aromatics & $\mathrm{C} 15 \mathrm{H} 24$ & 204 & 9.851 & 1.97 \\
\hline 11 & 1H-Cycloprop[e]azulen-7-ol & Terpenoid & $\mathrm{C} 15 \mathrm{H} 24 \mathrm{O}$ & 220 & 10.906 & 1.29 \\
\hline 12 & Caryophyllene oxide 5-Oxatricyclo[8.2.0.0(4,6)-]dodecane & Terpenoid & $\mathrm{C} 15 \mathrm{H} 24 \mathrm{O}$ & 220 & 11.176 & 1.73 \\
\hline 13 & Alpha.-Tetralone & Aromatics & $\mathrm{C} 12 \mathrm{H} 13 \mathrm{FO} 3$ & 224 & 11.279 & 6.24 \\
\hline 14 & 2-Naphthalenemethanol & Aromatics & $\mathrm{C} 15 \mathrm{H} 26 \mathrm{O}$ & 222 & 12.318 & 2.84 \\
\hline 15 & 2-Naphthalenemethanol & Aromatics & $\mathrm{C} 15 \mathrm{H} 26 \mathrm{O}$ & 222 & 15.545 & 0.98 \\
\hline 16 & Hexadecanoic acid & Fatty acid & $\mathrm{C} 17 \mathrm{H} 34 \mathrm{O} 2$ & 270 & 17.648 & 0.60 \\
\hline 17 & 1,4-Naphthalenedione & Phenolic & $\mathrm{C} 11 \mathrm{H} 8 \mathrm{O} 5$ & 220 & 18.672 & 1.07 \\
\hline 18 & 4H-1-Benzopyran-4-one & Flavonoids & $\mathrm{C} 16 \mathrm{H} 20 \mathrm{O} 4$ & 276 & 19.168 & 2.12 \\
\hline 19 & Ethanone & Phenolic & $\mathrm{C} 16 \mathrm{H} 14 \mathrm{O} 4$ & 234 & 19.563 & 4.34 \\
\hline 20 & 9,12-Octadecadienoic acid (Z,Z)-, & Fatty acids & $\mathrm{C} 19 \mathrm{H} 34 \mathrm{O} 2$ & 294 & 21.327 & 1.90 \\
\hline 21 & Octadecanoic acid & Fatty acid & $\mathrm{C} 19 \mathrm{H} 38 \mathrm{O} 2$ & 298 & 22.779 & 0.68 \\
\hline 22 & 1-Heptacosanol & Straight chain & $\mathrm{C} 27 \mathrm{H} 56 \mathrm{O}$ & 396 & 40.363 & 0.85 \\
\hline 23 & Alpha Tocopherol (vit E) & Phenolic & $\mathrm{C} 29 \mathrm{H} 50 \mathrm{O} 2$ & 430 & 40.600 & 0.47 \\
\hline 24 & Sitosterol, Stigmast-5-en-3-ol & Terpenoids & $\mathrm{C} 29 \mathrm{H} 50 \mathrm{O}$ & 414 & 42.438 & 0.57 \\
\hline 25 & Sitosterol, Stigmast-5-en-3-ol & Terpenoids & $\mathrm{C} 29 \mathrm{H} 50 \mathrm{O}$ & 414 & 43.399 & 3.88 \\
\hline 26 & Urs-12-en-28-al & Terpenoids & $\mathrm{C} 30 \mathrm{H} 48 \mathrm{O}$ & 424 & 44.480 & 1.47 \\
\hline 27 & Urs-12-en-28-al & Terpenoids & $\mathrm{C} 30 \mathrm{H} 48 \mathrm{O}$ & 424 & 45.816 & 4.93 \\
\hline 28 & Urs-12-en-28-al, 3-(acetyloxy)-, & Terpenoids & $\mathrm{C} 32 \mathrm{H} 50 \mathrm{O} 3$ & 482 & 47.628 & 1.49 \\
\hline 29 & Betulin \$\$ Lup-20(29)-ene-3,28-diol, & Terpenoids & $\mathrm{C} 30 \mathrm{H} 50 \mathrm{O} 2$ & 442 & 47.949 & 3.68 \\
\hline 30 & Urs-12-en-28-al & Terpenoids & $\mathrm{C} 30 \mathrm{H} 48 \mathrm{O}$ & 424 & 48.690 & 3.00 \\
\hline 31 & 3.beta.-Myristoylolean-12-en-28-ol & Terpenoids & $\mathrm{C} 44 \mathrm{H} 76 \mathrm{O} 3$ & 652 & 50.431 & 1.67 \\
\hline 32 & Urs-12-en-28-al & Terpenoids & $\mathrm{C} 30 \mathrm{H} 48 \mathrm{O}$ & 424 & 50.867 & 2.41 \\
\hline
\end{tabular}

previous studies have reported the antioxidant activities of some of these compounds [31, 32].

The results of the LC/MS analyses are presented in Table 3. Most of the observed compounds were typical hydroxycinnamic acid and phenolic acid derivatives (Fig. 1). The LC/MS analysis of the GF extract indicated the presence of caffeic acid phenyl ester, gingerol, aspidin, methyl orsellinic acid ester, ethyl ester, trans-2,3, 4trimethoxycinnamate, and metyrosine. In addition, the GL extract contained epigallocatechin 3-O-(4-hydroxybenzoate), 5,6,3'-trimethoxyflavone, metyrosine, gingerol, polygonolide, and trans-2, 3, 4-trimethoxycinnamate.
Total phenolic, total flavonoids contents, and antioxidant activity

Numerous phenolic metabolites containing an aromatic arene (phenyl) ring with one or more acidic hydroxyl residues attached to it are known to be produced by plants. A previous study showed that compounds such as flavonoid and tannins were among the major phenolic constituents present in plant extracts [33]. The phenolic radicals were reported to be less reactive and with a lower electron reducing potential than the oxygen radicals had [33, 34]. Because of these properties, phenolic compounds are considered excellent radical scavengers. 
Table 3 Chemical composition comparison of methanol extract from flower, and leaves extract of M. cajuputi based on LCMS

\begin{tabular}{|c|c|c|c|c|c|c|}
\hline \multirow[t]{2}{*}{ Phytochemical extract } & \multicolumn{2}{|l|}{ GF extract } & \multicolumn{2}{|l|}{ GL extract } & \multirow[t]{2}{*}{ RT } & \multirow[t]{2}{*}{$\mathrm{m} / \mathrm{z}$} \\
\hline & presence & $\%$ Abundance & presence & \% Abundance & & \\
\hline Metyrosine & + & 0.6 & + & 0.39 & 13.072 & 194.08203 \\
\hline Methylorsellinic Acid, Ethyl Ester & + & 0.74 & + & 8.02 & 11.18 & 209.0822 \\
\hline Hydroxyibuprofen & + & 1.2 & + & 0.74 & 10.759 & 221.1184 \\
\hline Trans-2, 3, 4-Trimethoxycinnamate & + & 0.7 & + & 11.61 & 10.386 & 237.07724 \\
\hline Gingerol & + & 0.45 & + & 0.28 & 11.768 & 293.17629 \\
\hline Catharanthine & + & 2.1 & + & 1.0 & 20.202 & 371.15374 \\
\hline calicoferol D & + & 1.1 & + & 0.65 & 21.489 & 409.31181 \\
\hline Caffeic acid Phenethyl ester (CAPE) & + & 18.69 & - & - & 18.451 & 283.30206 \\
\hline Aspidin & + & 0.65 & + & 0.59 & 12.819 & 459.20282 \\
\hline Cucurbitacin F & + & 1.2 & + & 1.2 & 20.886 & 517.31874 \\
\hline Kurilensoside G & + & 2.2 & + & 3.1 & 20.89 & 633.33896 \\
\hline $\begin{array}{l}\text { 1a,22,25-trihydroxy-26,27-dimethyl-23,23,24,24-tetradehydro-24a,24b, } \\
\text { 24c-trihomovitami }\end{array}$ & + & 9.68 & + & 9.48 & 20.869 & 497.36525 \\
\hline
\end{tabular}

Rt Retention time (as $\mathrm{min}$ ), $\mathrm{m} / \mathrm{z}$ mass

Furthermore, phenolic compounds are able to scavenge reactive oxygen intermediates without invoking further oxidative reactions. Therefore, one of the current standards of phytochemical research is the evaluation of the TPC as a measure of determining the antioxidant activity of extracts. Therefore, the current study evaluated the TPC of the extracts and found that the GF extract showed a higher value than the GL extract did ( $55 \pm 0.05$ and $37 \pm 0.05 \mathrm{GAE} / \mathrm{mg}$ extract dry weight, respectively). A similar trend was also observed with the flavonoids content of both extracts (Table 4, GF $>$ GL extracts). However, it is not surprising that the higher TPC value of the GF confers a stronger antioxidant ability than that of the GL. Therefore, the higher the TPC content of an extract, the higher its antioxidant activity will be. This is because the substituted $5,7,3^{\prime}, 4^{\prime}$-hydroxy flavonoids are believed to possess a very efficient radical scavenging power [35]. This observation was in agreement with the report of a direct relationship between the flavonoid and phenolic contents and the biological activities of plant extracts [36-38].

\section{DPPH radical scavenging activity}

The direct and rapid reaction between DPPH radicals and antioxidants has been utilized as a measure of antioxidant activity [39] and a high percentage DPPH radical scavenging of a compound indicates excellent activity. In this present study, the free-radical scavenging activity of the GL and GF methanolic extracts, which was evaluated using DPPH, was found to agree with TPC observation. Therefore, the extract with the higher TPC value also showed a higher percentage DPPH radical scavenging activity (Fig. 2). Furthermore, in agreement with the $\mathrm{TPC}$ and flavonoid observations, the percentage radical inhibition by GF extract was also higher than that of the GL extract was (81 and $75 \%$, respectively). This observation confirmed that both the GF and GL extracts exhibited DPPH radical-scavenging activity concentrationdependently, although only the GL extract showed a scavenging power that was greater than the values obtained with the BHT positive control. For both samples, however, increasing the concentration beyond $250 \mu \mathrm{g} / \mathrm{mL}$ resulted in a negligible increase in the radical scavenging activity (Fig. 2). Based on the calculated $\mathrm{IC}_{50}$ values, only the GL extract revealed a higher scavenging effect than the GF extract by demonstrating a lower $\mathrm{IC}_{50}$ value $(10 \mu \mathrm{g} / \mathrm{mL})$ than the positive control BHT $(13 \mu \mathrm{g} / \mathrm{mL})$; the GF extract showed an $\mathrm{IC}_{50}$ value of $25 \mu \mathrm{g} / \mathrm{mL}$. Several reports have indicated that free radical scavenging activity is greatly influenced by the phenolic contents of the sample, flavonoid, and the presence of hydroxycinnamic acids such as caffeic acid phenyl ester [40-42]. Similarly, high antioxidant activity was previously reported in Melaleuca [43].

\section{$\mathrm{Fe}^{2+}$-chelating activity}

In cellular lipid peroxidation determination, the Fenton reaction is used in metal chelating activity assays to reduce the concentration of the catalyzing transition metal. This kind of chelating reaction is considered significant in reducing the oxidative stress generated by reactive oxygen species. The chelating effect of the methanolic extracts was around $50 \%$ at an extract concentration of around $0.4 \mathrm{mg} / \mathrm{mL}$, and the chelating activity was concentrationdependent (Fig. 3). As expected, the activity of the GF extract was higher than that of the GL extract was, with maximum chelating activities of $\sim 75$ and $59 \%$, respectively (Fig. 3). The presence of a significant amount of caffeic acid phenyl ester in the GF may have contributed to this activity 
<smiles>CCCCC[C@H](O)CC(=O)CCc1ccc(O)c(OC)c1</smiles>

Table 4 A comparison of total phenolic and flavonoids contents

\begin{tabular}{lcc}
\hline Methanolic Extract & Total phenolic content (GAE/mg dw) & Total flavonoid content (QE/mg dw) \\
\hline M. cajuputi flower extract & $55 \pm 0.03$ & $19.6 \pm 0.4$ \\
M. cajuputi leaves extract & $37 \pm 0.02$ & $10.2 \pm 0.2$ \\
\hline
\end{tabular}




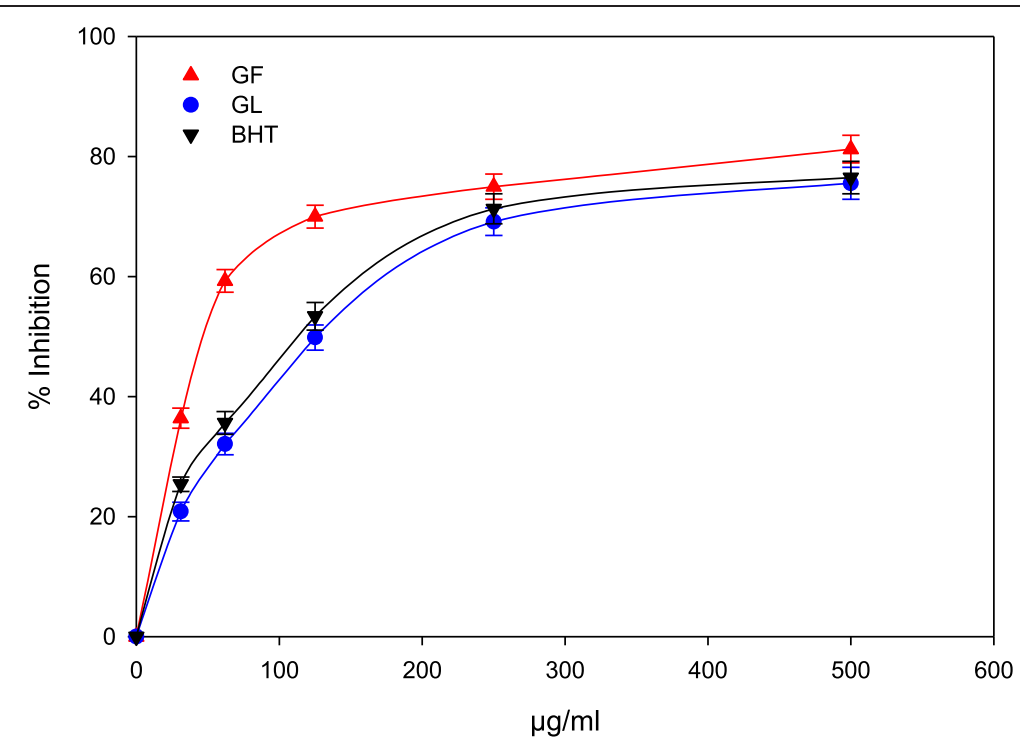

Fig. 2 Antioxidant activity of M. cajuputi flower and leaves extracts following DPPH radical scavenging assay

as these substances have been reported to exhibit strong chelating activity [44].

All the samples tested exhibited a logarithmic increase in chelating power with increasing concentrations up to $0.25 \mathrm{mg} / \mathrm{mL}$ and, thereafter, the percentage chelating activity appeared to increase gradually.

\section{$\beta$-Carotene bleaching test}

Carotenoids are among the most common natural pigments and are responsible for most of the red, orange, and yellow coloration of plant leaves, fruits, and flowers [45]. Currently, more than 600 different carotenoid compounds were reported to have been characterized [45]. In animals, carotenoids act as antioxidants. Furthermore, carotenoids have attracted much attention because numerous studies have revealed that their consumption is correlated with a diminished risk for several degenerative disorders including various types of cancer and cardiovascular or ophthalmological diseases [45]. This effect is attributed to their antioxidant activity, which protects cells and tissues from oxidative damage [45]. In this study, all the analyzed samples inhibited the discoloration of $\beta$-carotene in a concentration-dependent manner (Fig. 4). Generally, an increase in the percentage inhibition was observed with

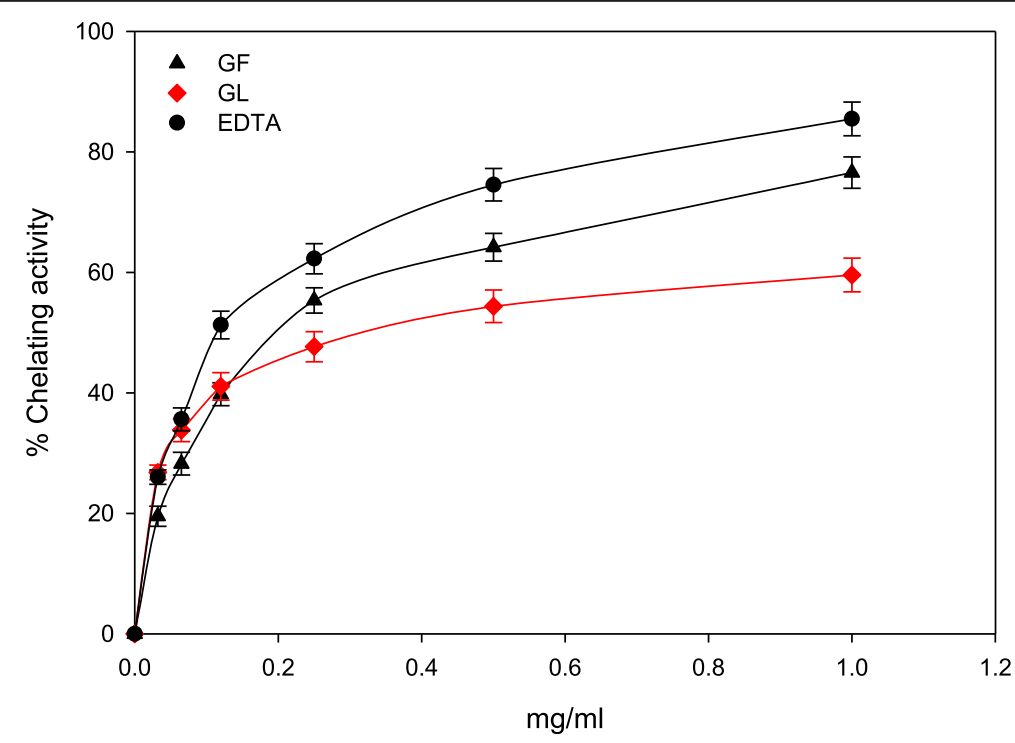

Fig. 3 Metal chelating activity of M. cajuputi flower and leaf extracts 


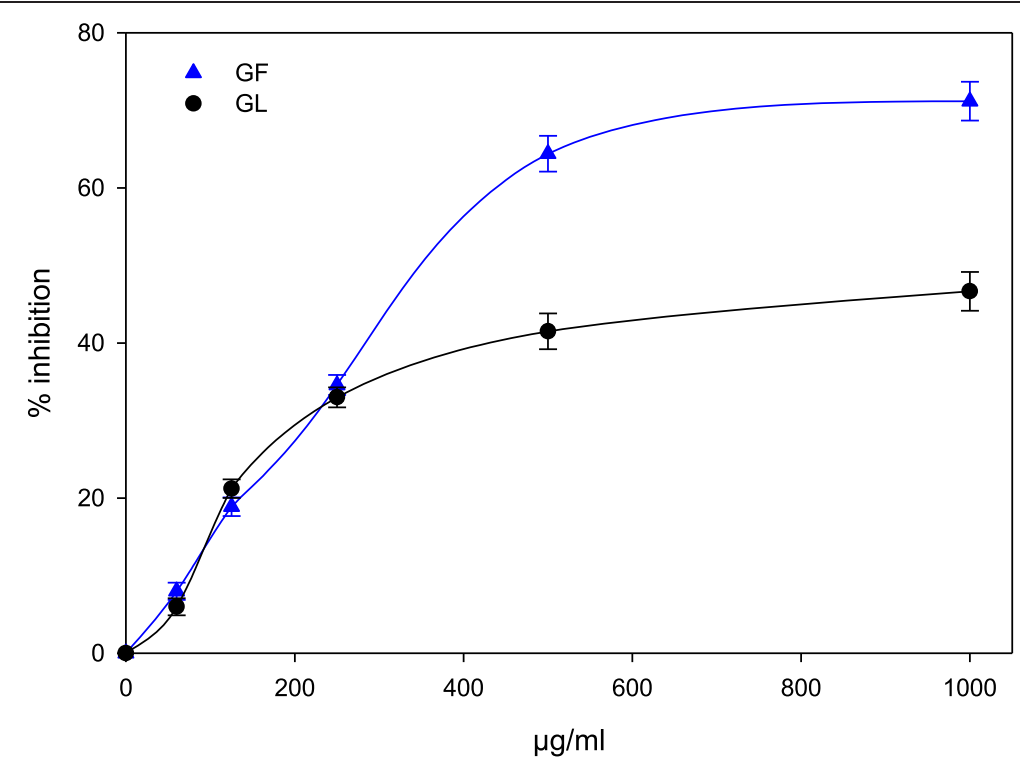

Fig. 4 Antioxidant activity of $M$. cajuput flower and leaf extracts determined by $\beta$-carotene bleaching test

all the samples tested. As expected, the GF extract was more effective than the GL extract was with inhibition rates of 71 and $47 \%$, respectively.

\section{FRAP assay}

The FRAP assay is primarily based on the principle of reduction of ferric ions to their ferrous form at a lower $\mathrm{pH}$, which results in the formation of a chromatic ferroustripyridyltriazine complex [46]. This assay is considered to be an accurate method for testing the antioxidant power of therapeutic compounds [47]. In this research study, the FRAP antioxidant ability of the $M$. cajuputi extracts in reducing the $\mathrm{Fe}^{3+}-\mathrm{TPTZ}$ reagent was evaluated and both extracts (GL and GF) demonstrated some reducing power with FRAP values of 0.12 and $0.14 \mu \mathrm{M} \mathrm{Fe}(\mathrm{II}) / \mathrm{g}$, respectively. The presence of a significant amount of caffeic acid phenyl ester in the GF extract likely contributed to its higher FRAP value than that of GL extract since this compound is known to possess strong FRAP antioxidant activity [44]. Zunjar and colleagues [36] reported that the reducing capacity of a compound may serve as a remarkable indicator of its antioxidant activity and ability to ameliorate oxidative stress by reacting with certain precursors.

\section{Antibacterial activity}

The antibacterial activity of the $M$. cajuputi extracts was evaluated against four Gram-positive (B. cereus, $S$. epidermidis, $S$. aureus, and $S$. pneumoniae) and four Gram-negative (E. coli, P. multocida, K. pneumoniae, and S. typhimurium) bacteria. The antibacterial activity of the extracts was assessed by determining their IZ, MIC, and $\mathrm{MBC}$ values (Tables 5 and 6).

The results revealed that both the GL and GF extracts potently inhibited S. epidermidis, S. aureus, and B. cereus (Table 5). The GF extract was more effective than GL against $S$. epidermidis and B. cereus, while both extracts showed comparable activity against $S$. aureus. However, both extracts had no effect against the tested Gramnegative organisms and $P$. multocida. The most susceptible

Table 5 Antibacterial activity of crude extracts

\begin{tabular}{|c|c|c|c|c|c|c|c|c|}
\hline \multicolumn{9}{|c|}{ Inhibition diameter $(\mathrm{mm} \pm \mathrm{SD})$} \\
\hline Sample & $\begin{array}{l}\text { Staphylococcus } \\
\text { epidermidis } \\
\text { (Gram + ve) }\end{array}$ & $\begin{array}{l}\text { Staphylococcus } \\
\text { aureus } \\
\text { (Gram + ve) }\end{array}$ & $\begin{array}{l}\text { Bacillus } \\
\text { cereus } \\
\text { (Gram + ve) }\end{array}$ & $\begin{array}{l}\text { Pasteurllamultocida } \\
\text { (Gram + ve) }\end{array}$ & $\begin{array}{l}\text { Klebsiella } \\
\text { pneumonia } \\
(\text { Gram + ve) }\end{array}$ & $\begin{array}{l}\text { Streptotococcus } \\
\text { pneumonia } \\
\text { (Gram + ve) }\end{array}$ & $\begin{array}{l}\text { Esherichia } \\
\text { coli } \\
\text { (Gram -ve) }\end{array}$ & $\begin{array}{l}\text { Salmonella } \\
\text { typhimurium } \\
\text { (Gram -ve) }\end{array}$ \\
\hline $\begin{array}{l}\text { M.cajuputi } \\
\text { Leaves }\end{array}$ & $13.66 \pm 0.43$ & $12.33 \pm 0.57$ & $6.33 \pm 0.33$ & - & - & - & - & - \\
\hline $\begin{array}{l}\text { M.cajuputi } \\
\text { flower }\end{array}$ & $17.33 \pm 0.36$ & $12.33 \pm 0.31$ & $12.33 \pm 0.48$ & - & - & - & - & - \\
\hline $\begin{array}{l}\text { Streptomycin } \\
\text { sulfate }^{a}\end{array}$ & $20.33 \pm 0.38$ & $18.0 \pm 0.2$ & $21.0 \pm 0.25$ & $21.0 \pm 0.05$ & $20.0 \pm 0.1$ & $22.0 \pm 0.08$ & $15.0 \pm 0.1$ & $10.0 \pm 0.2$ \\
\hline
\end{tabular}

${ }^{\mathrm{a}}$ Doses of Streptomycin was $1 \mathrm{mg} / \mathrm{ml}$

-No Activity observed 
Table 6 MIC and MBC of M. cajuputi extracts

\begin{tabular}{|c|c|c|c|c|c|c|}
\hline \multirow[b]{2}{*}{ SAMPLE } & \multicolumn{3}{|l|}{$\mathrm{MIC}(\mathrm{mg} / \mathrm{mL})$} & \multicolumn{3}{|l|}{$\mathrm{MBC}(\mathrm{mg} / \mathrm{mL})$} \\
\hline & Staphylococcus aureus & Staphylococcus epidermidis & Bacillus cereus & Staphylococcus aureus & Staphylococcus epidermidis & Bacillus cereus \\
\hline G.L. & 12.5 & 12.5 & NA & 25 & 25 & $N A^{* *}$ \\
\hline G.F. & 12.5 & 25 & 12.5 & 50 & 25 & 50 \\
\hline Streptomycin* & 1.95 & 1.95 & $>1.0$ & 1.95 & 1.95 & $>1.0$ \\
\hline
\end{tabular}

*Doses of Streptomycin was $1 \mathrm{mg} / \mathrm{ml}$

${ }^{* *}$ NA No Activity observed

bacteria to the GF extract were S. aureus, S. epidermidis, and $B$. cereus with MIC values of $12.5,12.5$, and $25 \mathrm{~g} / \mathrm{mL}$, respectively. Furthermore, the results showed there were no observed MIC and MBC values against $B$. cereus exposed to the GL extract (Table 6). However, the exposure of $S$. aureus to both extracts resulted in identical MIC, and $\mathrm{MBC}$ values 12.5 , and $25 \mathrm{mg} / \mathrm{mL}$, respectively.

The MBC for the GF extract against S. epidermidis was $25 \mathrm{mg} / \mathrm{mL}$, which was more effective than the GL extract was at $50 \mathrm{mg} / \mathrm{ml}$. These findings are of great significance, especially in the case of $S$. aureus and $B$. cereus that are well-known for being resistant to numerous antibiotics. In addition, these organisms are capable of producing several types of enterotoxins that can cause septicaemia and several forms of enteritis. In general, the GF extract was found to be active against some species of Staphylococci and Bacilli while the GL extract was inactive against the tested Bacilli. Therefore, the antibacterial activity of the extracts could be correlated with their phenolic and flavonoids contents. KA Hammer, C Carson and T Riley [13] reported a similar observation for the antimicrobial activity of $M$. cajuputi extract against $S$. aureus. In contrast, it was reported that the hexane, dichloromethane, and acetone extracts of $M$. cajuputi leaves showed no activity against $S$. aureus, methicillin-resistant $S$. aureus, E. coli, and P. aeruginosa [26].

\section{Conclusions}

We attempted to explore the diverse phytochemical efficacy of $M$. cajuputi against several diseases and oxidative stress, by evaluating the antioxidant and antibacterial activities of its GF and GL methanolic extracts. Furthermore, to the best of our knowledge, this is the first comprehensive study of the antioxidant and antibacterial potential of the GF and GL extracts. Generally, the GF extract showed a higher efficacy than the GL extract did. In addition, the TPCs were higher in the GF extract than they were in the GL extract, and these results were in agreement with the percentage radical inhibition results, which were higher for the GF extract than they were for the GL extract. The same trend was also observed in the $\mathrm{Fe}^{2+}$-chelating activity, flavonoid contents, and $\beta$-carotene bleaching test. Both extracts showed promising evidence of antibacterial activity against $S$. aureus, S. epidermidis, and
B. cereus. Finally, the observed antioxidant and antibacterial activities of these extracts could be attributed to the high content of phenolics and flavonoids identified using LC/MS and GC/MS.

\section{Competing interests}

The authors declare that they have no competing interests.

\section{Authors' contributions}

NMA participated in all face of the study, collection plant, conceived of the study, design and wrote the manuscript, ZMN design the study and rewrote the final one. MM, MSH supervised part of the study and reviewed the manuscript. MK participated in the design and coordination. FA participated in the chemistry part. All authors read and approved the final manuscript.

\section{Acknowledgement}

The authors are grateful to University of Malaya for research grant PG0852012B. The authors acknowledge the contribution of Abdulwali and azdren for the technical assistance in antioxidant and antibacterial activity.

\section{Author details}

${ }^{1}$ Department of Parasitology, Faculty of Medicine, University of Malaya, 50603 Kuala Lumpur, Malaysia. ${ }^{2}$ Department of Anesthesiology, Faculty of Medicine, University of Malaya, 50603 Kuala Lumpur, Malaysia. ${ }^{3}$ Department of Chemistry, Faculty of Science, University of Malaya, 50603 Kuala Lumpur, Malaysia.

Received: 22 February 2015 Accepted: 13 October 2015

Published online: 24 October 2015

\section{References}

1. Nagmoti DM, Khatri DK, Juvekar PR, Juvekar AR. Antioxidant activity free radical-scavenging potential of $<i>$ Pithecellobium dulce $</ i>$ Benth seed extracts. Free Radicals Antioxid. 2012;2(2):37-43.

2. Velioglu Y, Mazza G, Gao L, Oomah B. Antioxidant activity and total phenolics in selected fruits, vegetables, and grain products. J Agric Food Chem. 1998:46(10):4113-7.

3. Madhuri S, Pandey G. Some anticancer medicinal plants of foreign origin. Curr Sci. 2009;96(6):779-83.

4. Ito N, Fukushima S, Hagiwara A, Shibata M, Ogiso T. Carcinogenicity of butylated hydroxyanisole in F344 rats. J Natl Cancer Inst. 1983;70(2):343-52.

5. Stewart $P$, Boonsiri $P$, Puthong $S$, Rojpibulstit P. Antioxidant activity and ultrastructural changes in gastric cancer cell lines induced by Northeastern Thai edible folk plant extracts. BMC Complement Altern Med. 2013;13:60.

6. Negro C, De Bellis L, Miceli A. Antioxidant activity of Buglossoides purpureocaerulea (L.) IM Johnst. extracts. Nat Prod Res. 2013;27(4-5):509-12.

7. Parimala M, Shoba FG. In vitro antimicrobial activity and HPTLC analysis of hydroalcoholic seed extract of Nymphaea nouchali Burm. f. BMC Complement Altern Med. 2014;14(1):361.

8. Ayaz M, Junaid M, Ahmed J, Ullah F, Sadiq A, Ahmad S, et al. Phenolic contents, antioxidant and anticholinesterase potentials of crude extract, subsequent fractions and crude saponins from Polygonum hydropiper $\mathrm{L}$. BMC Complement Altern Med. 2014;14(1):145.

9. Liu J. Pharmacology of oleanolic acid and ursolic acid. J Ethnopharmacol. 1995;49(2):57-68.

10. Wolter F, Clausnitzer A, Akoglu B, Stein J. Piceatannol, a natural analog of resveratrol, inhibits progression through the $S$ phase of the cell cycle in colorectal cancer cell lines. J Nutr. 2002;132(2):298-302. 
11. Saravanan R, Pugalendi V. Impact of ursolic acid on chronic ethanol-induced oxidative stress in the rat heart. Pharmacol Rep. 2006;58(1):41-7.

12. Monzon R. Traditional medicine in the treatment of parasitic diseases in the Philippines. Southeast Asian J Trop Med Public Health. 1995;26(3):421-8.

13. Hammer KA, Carson CF, Riley TV. Antimicrobial activity of essential oils and other plant extracts. J Appl Microbiol. 1999;86(6):985-90.

14. Sfeir J, Lefrancois C, Baudoux D, Derbre S, Licznar P. In Vitro Antibacterial Activity of Essential Oils against Streptococcus pyogenes. Evid Based Complement Altern Med. 2013;2013:269161.

15. Ghasemzadeh A, Jaafar HZ, Rahmat A. Effects of solvent type on phenolics and flavonoids content and antioxidant activities in two varieties of young ginger (Zingiber officinale Roscoe) extracts. J Med Plant Res. 2011;5(7):1147-54.

16. Kim D-O, Jeong SW, Lee CY. Antioxidant capacity of phenolic phytochemicals from various cultivars of plums. Food Chem. 2003;81(3):321-6.

17. Mensor LL, Menezes FS, Leitão GG, Reis AS, Santos TC, Coube CS, et al. Screening of Brazilian plant extracts for antioxidant activity by the use of DPPH free radical method. Phytother Res. 2001;15(2):127-30.

18. Loizzo MR, Pugliese A, Menichini F. Radical Scavenging, Antioxidant and Ferric Reducing Activities of Commercial Mineral Water Enriched with Fruit and Ready to Drink Flavoured Teas. Open Nutraceuticals J. 2012;5:160-8.

19. Zainol MI, Yusoff KM, Yusof MYM. Antibacterial activity of selected Malaysian honey. BMC Complement Alter Med. 2013;13(1):129.

20. Wiegand I, Hilpert K, Hancock RE. Agar and broth dilution methods to determine the minimal inhibitory concentration (MIC) of antimicrobial substances. Nat Protoc. 2008;3(2):163-75.

21. Nicoletti M, Goulart MO, de Lima RA, Goulart AE, Monache FD, Bettolo GM. Flavonoids and alkaloids from Strychnos pseudoquina. J Nat Prod. 1984;47(6):953-7.

22. Li K-L, Sheu S-J. Determination of flavonoids and alkaloids in the scute-coptis herb couple by capillary electrophoresis. Anal Chim Acta. 1995;313(1-2):113-20.

23. Sakasegawa M, Hori K, Yatagai M. Composition and antitermite activities of essential oils from Melaleuca species. J Wood Sci. 2003;49(2):181-7.

24. Silva CJ, Barbosa LCA, Maltha CRA, Pinheiro AL, Ismail FMD. Comparative study of the essential oils of seven Melaleuca (Myrtaceae) species grown in Brazil. Flavour Fragrance J. 2007;22(6):474-8.

25. Yoon Y, Sornnuwat Y, Kim J, Liu K, Kitirattrakarn T, Anantachoke C. Essential Leaf Oils from Melaleuca cajuputi. In: III WOCMAP Congress on Medicinal and Aromatic Plants-Volume 6: Traditional Medicine and Nutraceuticals 680: 2003; 2003: 65-72.

26. Rattanaburi S, Mahabusarakam W, Phongpaichit S, Carroll AR. A new chromone from the leaves of Melaleuca cajuputi Powell. Nat Prod Res. 2013;27(3):221-5.

27. Padalia RC, Verma RS, Chauhan A, Goswami P, Verma SK, Darokar MP. Chemical composition of Melaleuca linarrifolia Sm. from India: a potential source of 1,8-cineole. Ind Crop Prod. 2015;63:264-8.

28. Ireland BF, Hibbert DB, Goldsack RJ, Doran JC, Brophy JJ. Chemical variation in the leaf essential oil of Melaleuca quinquenervia (Cav.) S.T. Blake. Biochem Syst Ecol. 2002;30(5):457-70.

29. Chapple IL, Matthews JB, Wright HJ, Scott AE, Griffiths HR, Grant MM. Ascorbate and alpha-tocopherol differentially modulate reactive oxygen species generation by neutrophils in response to FcgammaR and TLR agonists. Innate immun. 2013;19(2):152-9.

30. Soumya V, Muzib Yl, Venkatesh P. GC-MS Characterization, in vitro Antioxidant and Antimicrobial Activity of Newly Isolated Oil from Edible Wild Bamboo Rice (Bambusa bambos). J Biologically Active Prod Nat. 2014;4(3):209-15.

31. Kraujalis $P$, Venskutonis PR. Supercritical carbon dioxide extraction of squalene and tocopherols from amaranth and assessment of extracts antioxidant activity. J Supercrit Fluids. 2013;80:78-85.

32. Singh A. Sitosterol as an antioxidant in frying oils. Food Chem. 2013:137(1):62-7.

33. Ainsworth EA, Gillespie KM. Estimation of total phenolic content and other oxidation substrates in plant tissues using Folin-Ciocalteu reagent. Nat Protocols. 2007:2(4):875-7.

34. Gillespie KM, Chae JM, Ainsworth EA. Rapid measurement of total antioxidant capacity in plants. Nat Protocols. 2007;2(4):867-70.

35. Tsimogiannis DI, Oreopoulou V. The contribution of flavonoid C-ring on the DPPH free radical scavenging efficiency. A kinetic approach for the 3',4'-hydroxy substituted members. Innovative Food Sci Emerg Technol. 2006;7(1-2):140-6.
36. Zunjar V, Mammen D, Trivedi BM. Antioxidant activities and phenolics profiling of different parts of Carica papaya by LCMS-MS. Nat Prod Res. 2015;29(22):2097-2099.

37. Rice-Evans CA, Miller NJ, Paganga G. Structure-antioxidant activity relationships of flavonoids and phenolic acids. Free Radic Biol Med. 1996;20(7):933-56

38. Stanković MS, Stefanović O, Čomić L, Topuzović M, Radojević I, Solujić S Antimicrobial activity, total phenolic content and flavonoid concentrations of Teucrium species. Cent Eur J Biol. 2012;7(4):664-71.

39. Milardović S, Iveković D, Grabarić BS. A novel amperometric method for antioxidant activity determination using DPPH free radical. Bioelectrochemistry. 2006;68(2):175-80.

40. Hajji M, Jarraya R, Lassoued I, Masmoudi O, Damak M, Nasri M. GC/MS and LC/MS analysis, and antioxidant and antimicrobial activities of various solvent extracts from $<\mathrm{i}>$ Mirabilis jalapa $</ \mathrm{i}>$ tubers. Process Biochem. 2010;45(9):1486-93.

41. Cheung L, Cheung PC, Ooi VE. Antioxidant activity and total phenolics of edible mushroom extracts. Food Chem. 2003;81(2):249-55.

42. Mishra $\mathrm{K}$, Ojha $\mathrm{H}$, Chaudhury NK. Estimation of antiradical properties of antioxidants using DPPH $<$ sup $></$ sup $>$ assay: A critical review and results. Food Chem. 2012;130(4):1036-43.

43. Batubara I, Mitsunaga T, Ohashi H. Screening antiacne potency of Indonesian medicinal plants: antibacterial, lipase inhibition, and antioxidant activities. J Wood Sci. 2009:55(3):230-5.

44. Göçer H, Gülçin İ. Caffeic acid phenethyl ester (CAPE): correlation of structure and antioxidant properties. Int J Food Sci Nutr. 2011;62(8):821-5.

45. Stahl W, Sies H. Antioxidant activity of carotenoids. Mol Asp Med. 2003:24(6):345-51.

46. Benzie IF, Strain J. The ferric reducing ability of plasma (FRAP) as a measure of "antioxidant power": the FRAP assay. Anal Biochem. 1996;239(1):70-6.

47. Gwaram NS, Ali HM, Abdulla MA, Buckle MJ, Sukumaran SD, Chung LY, et al. Synthesis, characterization, X-ray crystallography, acetyl cholinesterase inhibition and antioxidant activities of some novel ketone derivatives of gallic hydrazide-derived Schiff bases. Molecules. 2012;17(3):2408-27.

\section{Submit your next manuscript to BioMed Central and take full advantage of:}

- Convenient online submission

- Thorough peer review

- No space constraints or color figure charges

- Immediate publication on acceptance

- Inclusion in PubMed, CAS, Scopus and Google Scholar

- Research which is freely available for redistribution 